\title{
Forays into a Digital Yiddishland: Secular Yiddish in the Early Stages of the Coronavirus Pandemic
}

\author{
Rebecca Margolis ${ }^{1}$ (1)
}

Received: 25 October 2020 / Accepted: 25 May 2021 / Published online: 20 July 2021

(c) Crown 2021

\begin{abstract}
The self-isolation and social distancing associated with the COVID-19 coronavirus pandemic added a new dimension to a multifaceted and transnational secular Yiddish social landscape. The widespread use of digital communication technologies facilitated new forms of virtual participation in a heterotopic Yiddishland via lectures, concerts, classes and conversation groups. This study examines engagement with secular Yiddish mediated by digital technologies during the early lockdowns and restrictions from March to May 2020. It investigates the expansion of a cybervernacular mode of Yiddish in a virtual secular Yiddishland encompassing learners, speakers, activists and performers worldwide, and the roles that secular Yiddish social spaces played for their participants during the crisis.
\end{abstract}

Keywords Secular Yiddish · COVID-19 Coronavirus pandemic · Yiddishland . Heterotopic Yiddishland · Postvernacular Yiddish • Cybervernacular Yiddish . Digital cultures $\cdot$ Jewish new media studies $\cdot$ Digital sociality

\section{Introduction}

The earliest lockdowns, restrictions and social isolation of the COVID-19 pandemic in March of 2020 prompted the widespread use of digital communication technologies to facilitate virtual participation in Yiddish-language programming worldwide. As face-to-face engagement was abruptly partially or completely halted under social distancing and other restrictions, the earliest research articles were already identifying the mental health issues associated with human isolation resulting from the pandemic (e.g., Webb 2020). In the secular Yiddish world, a gamut of nonprofit organizations as well as individuals deftly mobilized to establish innovative digital social spaces. Members of a dispersed community of Yiddish teachers, learners, musicians and enthusiasts gathered on digital video communication platforms

Rebecca Margolis

rebecca.margolis@monash.edu

1 Monash University, Melbourne, Australia 
such as Zoom to socialize, study the language, chat, learn new songs, and otherwise partake in the diverse offerings of the modern Yiddish cultural world. As previously existing in-person Yiddish gatherings moved onto digital platforms alongside fresh forms of programming, Yiddishists could fill their schedules with a wide array of online Yiddish-language activities that encompassed interconnected networks of speakers worldwide. The fluidity virtual sessions, with ease of access, entry and exit and often offered at no cost, facilitated participants moving between multiple Yiddish social spaces to build a sense of community rooted in shared interests in heritage, politics or culture. Through a snapshot of the first three months of global coronavirus restrictions-March to May of 2020 - this study investigates how digitally mediated Yiddish-language social spaces spurred by the pandemic galvanized a geographically dispersed secular Yiddishland.

The secular Yiddishland of the COVID-19 "new normal" represents an outgrowth of a diaspora civilization that had evolved as decentralized, global and inter-linguistic. The lingua franca of much of Ashkenazi Jewry over a thousand years, Yiddish was spoken by $75 \%$ of the world's 17 million Jews in 1939 across a vast territory spanning Europe and its multiple, interconnected immigrant centers. Since that time, Yiddish has faced attrition on multiple fronts, with half of the world's speakers murdered in the Holocaust and its European cultural centers decimated; rapid linguistic acculturation among its migrants; and the hegemonic status of Hebrew as Jewish lingua franca in Israel and much of the diaspora. In the process, Yiddish has become associated with discourses of loss and revival, as well as innovative expressions of identity and creativity. Today Yiddish is spoken within two polarized groups: (1) Rapidly growing populations estimated at between 500,000 and one million Haredi (traditionalist or strictly Orthodox) Jews comprising the vast majority (Katz 2019, 554-555), specifically the transnational enclaves of Hasidim. Hasidic Yiddish speakers employ distinctive dialects of Yiddish on a day-to-day basis as a family and community vernacular in deliberate continuity with a traditional Eastern European past and boundary against the secular mainstream (see Biale 2018; Nove 2018), and have produced an array of Yiddish-language media linked to their language use (Waldman 2018). (2) An amorphous and geographically dispersed population of non-Haredi Yiddish speakers for whom the language is intertwined with heritage, identity or culture. This population includes an estimated 100,000-550,000 very elderly speakers raised in pre-Holocaust Europe (Katz 2019, 554-555), their descendants who have maintained a connection to the language, and smaller numbers of new learners of the language who have chosen to speak it and, in some cases, transmit it as a first language to their own children. This diffuse secular Yiddish group, or Yiddishland, exists in continuity with modern Yiddish culture, which has for the better part of a century relied on mediated networks to communicate, educate, impart a sense of community and engage speakers though activities that reach geographically dispersed populations. For this decentralized secular Yiddishland, which forms the focus of this study, Yiddish tends to function as a second/heritage/ learned language rather than as a daily spoken language that is transmitted within families across multiple generations; the language is often acquired and transmitted via formal study or within projects involving performance. Contact, interaction and community-building among members of a transnational secular Yiddishland have 
long been established, maintained and strengthened through digital communication technologies, beginning with listservs in the 1990s.

The activities that emerged in the pandemic adapted long-standing staples of the secular Yiddish world to new patterns of digital sociality. These encompassed the conversation groups, reading circles, classes and lecture series associated with the early twentieth-century reorientation of Yiddish as a modern vernacular as well as the basis for identity within a distinct subculture (for example, Cohen 2008). They also drew on the more recent additions to the secular Yiddish landscape: the immersive language and culture programs and music festivals that have become pillars of the secular Yiddish world over the last four decades (see Wood 2016). These activities shifted onto formats where digital communication technologies joined multiple participants in a shared virtual space such as a Zoom room. Further, the "new normal" of COVID-19 offered a particularly fertile online site for innovation in the secular Yiddish space, notably in enterprises piloted by newcomers to the Yiddish milieu. In the new and fluid digital communications landscape of the early pandemic, Yiddish activity had not become monetized, and much was available free of charge. Further, people remained receptive to the new format of digital engagement and had not yet become "oysegezoomt" (Zoomed out), a Yiddish neologism coined in 2020 to denote fatigue or boredom from excessive use of the Zoom platform.

In this study, I present a sampling of digital secular Yiddish activity during a transitional period from March to May of 2020, where those who speak, read, write, sing, perform, teach or otherwise engage with Yiddish were being abruptly shifted into online environments. I investigate how the online spaces that emerged in the pandemic bridged vast geographic distances to expand the scope of the virtual Yiddishverse, with a focus on both their creators and participants. I posit that the normalization of online engagement and new platforms for digital sociality in the secular Yiddish subculture offered a linguistic and cultural haven during the crisis of the pandemic. This study offers not a conclusive study of the impacts of the coronavirus restrictions on Yiddish, but rather a semi-ethnographic account of emerging trends within the circles in which I move as a scholar and teacher of Yiddish, and as a Yiddishist. Raised in secular Yiddish Montreal, I became a graduate student and active participant in New York's secular Yiddish milieu in the 1990s. I am a researcher of Yiddish culture, teacher of Yiddish language in various immersive programs, and academic who relocated from the University of Ottawa to Monash University (Melbourne) on the eve of the pandemic. My Yiddishland entails a loose and expansive community of academic colleagues, former and current students, fellow teachers, musicians, translators and activists who gather at conferences, Yiddish programs and festivals, and are linked by social media. The data for this study was gathered from early March to late May 2020 from social media and email event announcements, organization websites, and email/Facebook messenger/Zoom communication, as well as my own participation in the activities. A Facebook post (discussed below) yielded a dozen interviews conducted over email, Facebook IM, and Zoom 
with both event organizers and participants. ${ }^{1}$ With a focus on activities supporting active use of the Yiddish language such as Yiddish conversation groups or the creation of Yiddish-language materials, I sought to identify and analyze trends associated with the impacts of the coronavirus restrictions on Yiddish-language activity.

This study is limited in scope by its time frame and focus. I do not purport to be exhaustive in covering the wide range of activities offered in or about Yiddish during the COVID-19 pandemic. Rather, my analysis centers on activities with prominent Yiddish-language content (e.g., Yiddish-language videos) or held in Yiddish (e.g., discussion groups, classes or lectures held in Yiddish), rather than activities about Yiddish. My intent is to document the events and the perspectives of some of their creators and participants in a fleeting and ephemeral digital world where online events and experiences can easily vanish without a trace with the removal of a social media post or webpage. I do not examine the responses to the coronavirus pandemic in the Haredi world, which engaged in its own slate of online activity in Yiddish in novel ways. ${ }^{2}$ Nor do I investigate the many guises under which the language appeared online for a broader public that exists beyond the circles directly engaged with Yiddish. ${ }^{3}$ Rather, I explore emerging modes of engagement with secular Yiddish in the earliest weeks of the pandemic, collected and analyzed at the time during which they unfolded.

\section{Background: Digital Yiddishlands}

When the crisis of the pandemic propelled secular Yiddish into new arenas moderated by video communication platforms, it had already been firmly ensconced in the digital age. The very factors underlying suggestions of secular Yiddish as "dying" or "endangered"- - low numbers of daily speakers combined with a preponderance of chosen sites for engagement rather than daily usagetated ventures that employ digital technology to preserve, promote and revitalize the language. Nonprofit organizations as well as Yiddish enthusiasts across the Americas, Europe, Israel and Australia invested in the promotion of the language have increasingly stepped into the digital space to enhance Yiddish language learning and cultural engagement. These initiatives have served to promote

\footnotetext{
${ }^{1}$ I thank my respondents for their generosity in sharing their perspectives with me. This research was conducted with ethics approval from my home academic institution and permission to reproduce the Facebook citations.

${ }^{2}$ For example, leaders of the Hasidic community would create Yiddish-language promotional materials encouraging mask use among their adherents that were disseminated online. See "Wear a Mask," a short produced by the office of Rockland County, New York, by its Hasidic legislator, Aron B. Wieder, and posted to his YouTube channel on October 8, https://youtu.be/H6hJUymLtqI.

${ }^{3}$ To offer just two examples from the end of April, 2020: a popular media article titled, "These 10 Yiddish Words Will Get You Through Quarantine" offered a list of terms ending with "oy" (Scolnic and Eisenberg 2020); a magazine article on a Yiddish penny song called "Mentshn-fresser" (Man Eater) originally published during the influenza epidemic of a century earlier concluded, "As we face the consequences of the spread of COVID-19 we can endeavour to prevent it from becoming a menshen fresser as hungry as its predecessors" (Goldman 2020).
} 
a global community around Yiddish in multiple, often interconnected realms: as a shared spoken language; a medium of song, theatre or film; a literary tongue; a subject of research; a language to be studied or taught; and a vehicle of religious, political, heritage or personal identity. The robust pre-pandemic digital Yiddishverse emerged outside of a centralized academy or state-supported apparatus; only in Sweden, where Yiddish holds official language status, does the language receive sustained state support in the area of public broadcasting (Ingall 2019).

What follows is a small sample of the digital Yiddish infrastructure that predated the pandemic in the United States, the most expansive organizational center of secular Yiddish. In addition to Yiddish being taught online in university classrooms mediated by digital technology (see Legutko 2016), the New York-based Workers Circle/Arbeter Ring (formerly the Workmen's Circle) has over the last decade expanded its online Yiddish distance learning offerings at multiple language levels, from beginner through advanced (Workers Circle Yiddish). For learners seeking to access Yiddish resources, the Digital Yiddish Library of the Yiddish Book Center (Amherst, Massachusetts) hosts a digitized corpus of virtually all of Yiddish literature, with some 11,000 titles accessible online, alongside an extensive collection of audio materials (Yiddish Book Center). Yiddish audiovisual materials are featured in online exhibits and websites devoted to topics such as radio or theatre (Yiddish Radio Project, the Digital Yiddish Theatre Project). Contemporary newspapers and journals published online can be accessed free of charge: the Yiddish Forverts (Forward) newspaper, which adopted an entirely online format in 2019, features wide-ranging textual as well as original subtitled video content (Yiddish Forward); In Geveb: A Journal of Yiddish Studies, launched in 2015, offers a fully digital forum for the publication of peerreviewed academic research, blog articles, translated and annotated Yiddish texts, pedagogical materials, reviews and interviews (In geveb). A Yiddish course for the Duolingo language learning app — a mobile app available free of charge - was in its final stages of development (see Kutzik 2019). Yiddish projects created by organizations and individuals worldwide were disseminated by websharing sites such as YouTube, where subtitled Yiddish-content videos sometimes went viral (Yudelson 2019). Social media was widely used as a means of socializing, requesting or suggesting vocabulary or disseminating news about the Yiddish world. The above list of digital spaces where Yiddish learners could study, read and otherwise engage with the language points to the vitality of the digital Yiddishland even before the pandemic, and its capacity not merely to adapt to "the new normal" but to expand its footprint during the crisis. For example, the New York-based YIVO Institute for Jewish Research, which had offered online access to an array of Yiddish-language digital materials including film footage and periodicals, reported a $250 \%$ increase in traffic to its website by the end May (Kutzik 2020).

The digital secular Yiddishverse emerged out of a mode of Yiddish engagement that Jeffrey Shandler's often-cited study, Adventures in Yiddishland (2006), terms "postvernacular Yiddish." Here Yiddish occupies symbolic and performative rather than communicative functions as part of a radical transformation since the Holocaust: 
A new semiotic mode for the language, every utterance is enveloped in a performative aura, freighted with significance as a speech act quite apart from the meaning of whatever words are spoken... Increasingly, Yiddish speech must be willed into existence, constructed and monitored with unprecedented deliberateness. It has become, therefore, more performative in its very nature (Shandler 2006, 20-21).

Within this "postvernacular" mode, engaging with Yiddish is inherently international, something to be sought out and cultivated. Within "the trope of Yiddish as a dying or dead language," the associations between the language and the decimation of the Holocaust have situated Yiddish as "a compelling metonym for the tragic loss of its speakers" (Shandler 2006, 180, 18). Netta Avineri situates the discourse around Yiddish as endangered as a focal point of secular Yiddish, with its proponents forming a "metalinguistic community" for whom the language is core to group identity without necessarily being spoken or studied; rather, Yiddish is connected with an irretrievable past in "nostalgia socialization" (Avineri 2013). Yiddish holds special value as a key to a pre-Holocaust or immigrant past as well as rich literary, musical, performative and radical political legacies (see Rabinovitch 2012). Amelia Glaser suggests that Yiddish has increasingly become a cultural symbol not only in North America but more globally as it has shifted from a signifier (a mode of communication) to a signified (a subject unto itself). As a borderless diaspora language, it offers an inclusive expression of Jewishness and connections to both a collective memory and heritage and a collaborative and progressive subculture of the present, within and beyond the Jewish world (Glaser 2017).

As a chosen subculture, the twenty-first-century secular Yiddishland is particularly conducive to digital community-building and sociality. Outside of the Haredi world, the sites of connection with Yiddish language and culture hinge on dedicated spaces in events and gatherings held by, and for, chosen communities. With a longstanding association with leftist and queer identity politics, Yiddish offers a vehicle for meaningful discourse and expression on multiple levels. A primary site of transmission for secular Yiddish is the classroom, with engagement taking place among artists or members of subcommunities aligned around shared identities and ideologies. Yiddish is commonly encountered in a mode that scholar Abigail Wood has termed "heterotopic Yiddishland": "a new kind of vernacular use of Yiddish: aesthetic rather than ethnic or linguistic; embedded among rather than separated from other cultural forms" (Wood 2016, 103). Based on Michel Foucault's concept of heterotopia as spaces that exist outside of the regular patterns of public life, heterotopic Yiddishland entails intensive and transformative cultural, institutional or discursive Yiddish social spaces that serve to engage or empower their participants. For example, one of the mainstays of the secular calendar for the Yiddish community is the immersive and multiday music-based festival (e.g., Yiddish Summer Weimar) or intergenerational music camp (e.g., KlezKanada), which help to shape a community with a shared common denominator of secular Yiddish cultural literacy and where, "set apart from the outside world, Yiddish culture becomes a lived norm" (Wood 2016, 41). Secular Yiddish offers a space to enact a deeply meaningful cultural identity within a dispersed chosen community, and to enact the optimal version of the 
person one wants to be. In tandem with the continued renewal of interest in Yiddish among diverse subgroups, sites for identity-based and performative engagement with Yiddish mediated by communications technologies have been expanding as part of a decades-old Yiddish "revival" or "revitalization." In a global Yiddishland on the eve of the pandemic, it was not uncommon for friendships to exist exclusively in a virtual capacity or be kindled at in-person Yiddish gatherings but nurtured via digital technologies. During the crisis of a pandemic, where better to turn than to a chosen online community offered by Yiddish?

The coronavirus pandemic has brought into sharp focus what scholar Tsvi Sadan termed "cybervernacular" Yiddish in his study, "Yiddish on the Internet" (2011). Suggesting that non-Haredi Yiddish had entered a new stage in its sociological development, Sadan envisioned worldwide computer-mediated communication (CMC) — web, email, newsgroups, chat and instant messaging — offering the potential to form virtual speech communities among individual speakers or small pockets of speakers worldwide. Sadan's research concluded that the vast possibilities offered by the technology remained unrealized:

The Internet, especially websites and mailing lists, has a greater potential for diaspora languages like Yiddish than for non-diaspora languages for forming virtual communities, as the former have few non-virtual communities, while the latter already have communities outside the Internet. Yiddish has not fully used this potential, so the virtual community in Yiddish remains rather small. (Sadan 2011, 105)

Whereas the last ten years have introduced extensive and wide-ranging innovations to the Yiddish digital world, the coronavirus pandemic propelled the secular Yiddish world-like much of the world at large-into a cyber-based reality, mediated by digital technologies and screens. A multitude of online platforms, resources, and educational and cultural offerings to explore or participate in activities in the secular Yiddish world that existed on the eve of the pandemic laid the foundation for the turn to digital sociality and the burgeoning of virtual Yiddish social spaces under the coronavirus restrictions and lockdowns. The abrupt shift to online communications platforms at the start of the pandemic restrictions served as a further foray into cybervernacularity and the realization of a virtual Yiddish-based community.

Sadan's analysis emerged within broader academic discourse around digital sociality as well as Jewish new media studies. Scholars have explored optimal ways to design and build thriving online communities that benefit from the contributions and commitment of their members (e.g., Kraut 2011). Others have investigated the potential of online communities in promoting social change in a variety of global contexts, in particular via the establishment of digital ties among members (e.g., Parigi and Gong 2014). Studies of digital subcultural sociality have explored the ways in which subcommunities rely on digital technologies to enact their social lives and combat isolation, in particular youth with alternative sociocultural identities who sit outside of the mainstream and whose members are widely geographically dispersed (e.g., Goths or geeks, see Ragusa and Ward 2016). Indeed, as a chosen sociocultural identity, secular Yiddish has enacted forms of subcultural participation online since the 1990s, when the Mendele Listserv, a moderated mailing list related 
to the Yiddish language, ${ }^{4}$ began to offer an online forum for Yiddish exchange via English transliteration. The mode of a virtual Yiddishland, where engagement with secular Yiddish occurs via digital platforms, exists at the intersection of Yiddish studies and a growing scholarly literature on Jewish new media studies and digital cultures. This scholarship examines how users of digital technology negotiate their religious or ethnic identities and how new communication methods and online environments might shape the construction of their communities and worldviews. For example, studies explore the ways that the internet and social media platforms have been negotiated within the Orthodox Jewish world or have facilitated the emergence of innovative religious models within Judaism such as "pop-up" congregations for worship, particularly among younger Jews (see Abrams 2015; Campbell 2015). These studies have tended to examine the engagement of religious groups with new digital technologies against the values and norms of their communities. Whereas the significance of the Yiddish language as a vehicle for Holocaust memory in survivor testimony mediated by digital technology has been the subject of scholarly inquiry (Shandler 2017), the broader implications of new technology for the contemporary Yiddish world remain to be unpacked and investigated. As a chosen community that comprises diverse ideological perspectives and subcultures, the role of cyberspace in the formation of identities connected with secular Yiddish has become increasingly significant, with the coronavirus pandemic as a flashpoint.

\section{Findings}

During the period under discussion-March to May of 2020 — an array of accessible online Yiddish-language initiatives cropped up spontaneously via nonprofit organizations or as projects initiated by Yiddish scholars, activists or artists who found themselves restricted to their homes by the pandemic. These were spearheaded and attended by those in hubs of secular Yiddish (e.g., New York, Montreal, Melbourne, Paris, Tel Aviv), as well as in locations ordinarily remote from Yiddish activity. To offer a very few examples from around the world, accessible free of cost: the Yiddish Open Mic Café, an event showcasing Yiddish-language talent formerly held regularly in London, England, shifted to a new virtual format on Zoom and attracted international participation among both performers and audiences (April 26, May 17, 27; ongoing, Yiddish Open Mic Café). Idishe Shtub Mx, a Mexican Yiddish cultural group, hosted an online presentation combining discussion, slides and performance clips to spotlight Mexican Yiddish culture to participants worldwide (May 24, Idishe Shtub Mx). Montreal's Dora Wasserman Yiddish Theatre hosted "A Chasene in Shtetl (2016 concert) watch party!," which entailed the interactive streaming of an archived recording of a Yiddish-language play to spectators globally (May 17, A Chasene in Shtetl). The New York-based League for Yiddish featured its new editor, Miriam Trinh, leading a two-day seminar titled, "Di pandemye-akademye/Pandemics Academics" (May 24-25, Di pandemye-akademye), which examined literature

\footnotetext{
${ }^{4}$ Mendele https://mailman.yale.edu/mailman/listinfo/mendele, accessed 29 May 2020.
} 
about pandemics written in Yiddish. Vera Szabó's long-standing "Yiddish \& Yoga in Yerushalayim" classes were offered three times a week via Zoom for their regular participants in Israel as well as virtual newcomers worldwide (Yiddish \& Yoga in Yerushalayim). One comment I received in response to my Facebook research query for this article summed up the impetus behind some of these activities: "I have started taking online Yiddish classes for the first time in years. Nothing better to do, lots of new exciting opportunities to learn from people who don't live close to me" (Abbey Howell, Comment on Facebook Post, "Calling all Yiddish people," 24 May 2020).

Before beginning my analysis of various categories of initiatives, I wish to observe three general trends of the early-pandemic online secular Yiddish activities: (1) their accessibility, inclusiveness and broad reach; (2) the visibility of youth; and (3) the prevalence of second languages.

(1) As previously location- or organization-specific events moved online, they became accessible outside of their geographic or institutional footholds to the Yiddish world at large. Events that had previously required extensive and costly travel or membership in a group or organization became accessible through the mediation of technology, largely unmonetized and open to all. Geographic distance was eliminated as a barrier to attendance, assuming a participant was available and willing to participate across time zones at all hours of the day or night. The reach of nonprofit organizations dedicated to the promotion of Yiddish whose influence might have once been primarily local became international in scope. Rather than spearheaded through a coordinated or formalized clearinghouse of Yiddish activity, news of opportunities to learn, hear or speak Yiddish were disseminated through posting and sharing over social media by individuals who were themselves engaged with Yiddish. The pandemic spurred an expansion of online Yiddish engagement in ways that were fluid and decentralized and, in the process, eradicated barriers that previously might have limited participation-time and funds required for travel, issues around mobility, or knowledge of events - to create a more cohesive virtual secular Yiddish community. The announcements of activities embodied a rhetoric around opportunity and innovation associated with the pandemic secular Yiddish activity, and identifying the potential benefits of the interactive online format.

(2) Younger creators of, and participants in, new virtual initiatives involving secular Yiddish were particularly visible in the early weeks of the pandemic's turn to online programming. Already at home in the digital technologies that became so widespread during the coronavirus pandemic, the under- 40 cohort was able to mobilize to identify opportunities for digital Yiddish spaces and quickly make the transition to new digital platforms. In addition to the speakers, teachers and artists with a direct, family connection to pre-Holocaust Eastern European Yiddish, the early-pandemic Yiddish activity was spearheaded by younger newcomers to Yiddishland. Organizations with young people at the helm were particularly active in the expansion of the secular Yiddish social landscape mediated by digital technology. One example is the San Diego-based Yiddish Arts and Academics Association of North America (YAANA), formed by then-doctoral student Jana Mazurkiewicz Meisarosh in 2017 to promote Yiddish language and culture. YAANA responded quickly to the pandemic, beginning with a Facebook 
announcement on March 15 that it would be moving its language classes partially online, and soon forged ahead with an array of accessible online programming in Yiddish led by younger members of the organization, including weekly Yiddish yoga classes (ongoing beginning $30 \mathrm{March}$ ) and a webinar on Yiddish fantasy and science fiction (April 3). By the end of May, YAANA was planning to host a wide variety of online events aimed at a wide audience, including language classes at multiple levels, online conversations with Yiddish cultural figures, pedagogy session held in Yiddish, a reading club, lectures and musical events (Yiddish Arts and Academics Association of North America).

(3) A notable feature of these online Yiddish offerings was the pervasive scaffolding of a second language. For example, after observing the explosion of online Yiddish activity in the pandemic, I posted in English on my Facebook page:

Calling all Yiddish people: I am writing a research article about online community building during COVID-19. Please send me news about your projects-webinars, shmueskrayzn, concerts-formal or informal: rmargoli@ uOttawa.ca or IM me. I am also interested in talking with anyone who has found new ways to engage with Yiddish during "the new normal." A sheynem dank! (May 22)

I received replies from across the world-Australia, Canada, Israel, Japan, Russia, the United States-penned in one of the three different formats characteristic of online communication in the secular Yiddish world, or a combination thereof: Yiddish written in the Yiddish alphabet (Hebrew letters); Yiddish transliterated into English letters, a format that was widespread in digital Yiddish communication until Yiddish keyboards became widely accessible on computers and handheld devices (e.g., my "a sheynem dank," meaning "thank you"); and responses penned entirely in English. With secular Yiddish speakers invariably speaking at least one other language - most often English due to the prominence of the United States, Canada, Australia and the United Kingdom in the Yiddish world - the virtual Yiddishverse tends to be mediated by a second language, be it in social media event announcements, promotional materials, or the apparatus of subtitles out of Yiddish in videos. This pervasive presence of a second language underlines the postvernacular character of the digital Yiddish world, even when the language is being employed in a fully communicative manner within an activity such as a conversation group.

What follows is a sampling of virtual Yiddish-language initiatives from the first three months of the coronavirus pandemic moving from the metalinguistic-about Yiddish - to the linguistic — in Yiddish, where a significant degree of conversational skill is required: the virtual Yiddish concert and singalong; the Yiddish educational video; the immersive Yiddish experience; and the Yiddish chat. These point to the resilience of some of the core pillars of secular Yiddishland and their organizers, not only in their capacity to adapt but to frame the shift to a virtual format in a positive light as an opportunity to draw new participants and thereby expand the community. 


\section{The Virtual Yiddish Concert and Singalong}

Within the postvernacular or performative space, music offers an accessible and interactive mode to engage with Yiddish, particularly via singing. The coronavirus pandemic demanded sharp adjustments to the production and consumption of music, with entire seasons of performances canceled and a devastating impact on musicians and artists in terms of audiences and income. The "new normal" of the coronavirus radically altered the face of musical activity within the Yiddish world, with the Yiddish performance community seizing opportunities to experiment with new formats. One musical subcommunity of performers of the genre of Klezmer music, which is so closely entwined with secular Yiddish culture, responded by holding online "jam sessions" with participants from remote locations. For example, the Toronto-based klezmer group, The Oychestra band, presented a "quarantine collab of the great Sam Muziker's 'Sam's Bulgar' from Dave Tarras's 'Tanz!'” (May 19) in a pre-recorded and uploaded video performance featuring six musicians, each of whom were shown playing their instruments simultaneously in the online visual patchwork that has become so emblematic of virtual gatherings during the pandemic (The Oychestra). While the time lags of the existing digital technologies rendered simultaneous, spontaneous live performance impossible, the turn to digital platforms encouraged new kinds of projects and partnerships among musicians.

The pandemic sparked collaborations among Yiddish artists worldwide that might never otherwise have happened. A concert featuring performers from points of origin all over the globe, which would be prohibitively expensive and complex to coordinate, became feasible in an online gathering. In this vein, two Yiddish-oriented American organizations on opposite ends of the country coordinated an international gathering of performers to mark the 104th annual commemoration of the passing of beloved Yiddish writer Sholem Aleichem (May 24). The blurb for this widely advertised and promoted event, "Sholem Aleichem from every continent," read:

This year's Zoom craze has given us a special opportunity. The Congress for Jewish Culture and the California Institute for Yiddish Culture and Language, together with the participation of international Yiddish stars Mike Burstyn (Los Angeles), Mendy Cahan (Tel Aviv), Raphe Crystal (Bronx), friends from the Dora Wasserman Yiddish Theatre (Montreal), Elisa Gray and Tomi Kalinski (Melbourne), Lea Koenig (Tel Aviv), Miwa Kogure and Wataru Ohkuma (Tokyo), Caely-Jo Levy (Cape Town), Sasha Lurje (Berlin), Eleanor Reissa (New York), Miryem-Khaye Seigel (Brooklyn), Yelena Shmulenson (New York), Zisl Slepovitch (Brooklyn), and Viver com Yiddish (Rio de Janeiro), we have an ALL YIDDISH program with an international lineup of guests from every inhabited continent (negotiations with the last Yiddish-speaking king penguin in Antarctica fell through).

The 90-minute event, comprising recitation and musical performance in Yiddish, was held via the social media platform Facebook Live, and attracted more than 13,000 viewers in its first day of being posted, a significant number in the relatively small secular Yiddish world (Save the Music). The event marked a singular 
opportunity for a truly international cadre of musicians performing in Yiddish to join forces in a shared secular Yiddish space.

The pandemic spurred new activities that combined the act of Yiddish singing with digital technology in order to build community. For example, "The Yiddish Song of the Day," produced by Brooklyn-based artists Jeyn Levinson and John Waletzky, ran continuously beginning on March 19 and continued beyond the period under discussion in this paper. The duo had been coordinating weekly gatherings for their group, the Yiddish Singing Society, from their living room during the pandemic when Levinson suggested that they move to a daily online format. The audience size varied from 5 to 20 in the morning and evening and included former participants in the Yiddish Singing Society as well as Yiddish aficionados from around the globe. In an interview, Levinson identified their motivation as threefold:

(1) We have friends who are single and alone and are tuning in every single day as a touchstone - and they have told us it is absolutely keeping them going. (2) We have participants who have told us that they have a folder on their desktop of the songs we are teaching, and they are learning them all - so this is of course a dream outcome - that we are teaching Yiddish songs to folks for singing in social or performative situations. 3) It has been grounding me and Josh to think about songs that are connected to what we are all living through, and/ or songs that distract us, and/or songs that we love regardless of connection and to share them with people (Jeyn Levinson, Facebook Messenger interview with the author, 22, 26 May 2020).

Levinson's comments-employing the terms "grounding" and "connected"underline the deep significance of Yiddish cultural activity during the time of crisis and upheaval caused by the pandemic.

\section{The Yiddish Educational Video}

One avenue for delivering Yiddish educational programming in response to the social distancing restrictions was the posting of short videos on video-sharing platforms such as YouTube or on social media. For their viewers, these videos offer Yiddish interactions that are passive but can enhance their vocabulary as well as encourage a sense of connectedness to the language and wider community of speakers; for their creators, they can also be deeply meaningful as a way of verbalizing and disseminating their knowledge of the language or ideological perspectives around Yiddish to a community of viewers, real or imagined.

What follows are three video series that sit on the continuum of Yiddish use ranging from symbolic and mediated by English, to use of the language in a fully communicative manner. An early and enduring initiative during the pandemic was the launch of a "Yiddish Word of the Day" video series by the Yiddish, where the newspaper's editor, American-born native Yiddish speaker Rukhl Schaechter, offered short English-language videos to informally teach Yiddish vocabulary around a particular category of terminology (Forward Staff). For example, one two-minute video modeled and explained the etymology of terms of endearment such as 
"bubele" (posted April 29, Yiddish Terms of the Day). This activity, which required no Yiddish knowledge from its viewers, was accessible to a wide audience of Yiddish enthusiasts that included those with a purely symbolic relationship with the language. Two other video series frame Yiddish as a communicative language produced by younger newcomers to Yiddish. The first, launched by the Workers Circle/Arbeter Ring during the pandemic, introduced listeners to Yiddish terminology within the context of lighthearted Yiddish-language monologues scaffolded by English subtitling as well as strategically placed signs (e.g., as leaves on trees). The promotional blurb posted on social media on May 14 with the first video announced:

The Workers Circle is helping keep \#YiddishAlive! We've teamed with Yiddishist Mikhl Yashinsky (https://yashinsky.com/) to create a series of short, fun, educational videos that explore this vibrant and expressive language. This week's video is all about Friling/Spring! While many of us are stuck indoors, Mikhl took a socially distanced hike through natur/nature and is sharing some key Yiddish terms with us (\#Yiddishalive).

Yashinsky, who studied Yiddish as a young adult and co-authored a Yiddish textbook that employs a communicative approach (In Eynem) before embarking on a career with the New York-based National Yiddish Theatre company, presents a young, fluent speaker of the language. The inaugural video, which features Yashinsky as our affable companion, introduces the viewer to nature terminology by modeling pronunciation of terms such as "bletl" (leaf), while interweaving Yiddishist commentary such as "dos bletl is lebedik, vi yidish" (this leaf is alive, like Yiddish). Yashinsky, who speaks exclusively in Yiddish in the video, evinces a communicative approach to a postvernacular project that is accessible to a wide audience: his flowing Yiddish is scaffolded by English subtitles to render the video accessible to non-speakers, whose relationship with the language may vary from symbolic to vernacular. A second video series, Alice Che's YouTube channel, produced out of her home in Kaliningrad, Russia, features the Yiddish activist teaching Yiddish-language songs and offering politicized commentary on current events, entirely in Yiddish. While the series of videos predated the pandemic, her post-pandemic videos integrated her responses to the new realities of social distancing and handwashing (posted 9 April, Der 8 Merts). These videos embody Che's own vernacular relationship with Yiddish, which represents a significant component of her identity. In an interview, she observed that as a young learner of Yiddish in a remote location in Russia, the language offered a rich leftist and anarchist heritage that she embraced as an integral part of her Jewish identity; noting a dearth of engaging modern videos in Yiddish, she decided to make her own (Alice Che, email interview with the author, 23 June 2020). The medium of accessible short videos facilitates Yiddish teaching as well as the dissemination of ideologies associated with the language. 


\section{The Immersive Yiddish Experience}

The prominence of immersive events such as retreats or language programs on the calendar of secular Yiddish deftly shifted them into online formats in response to the pandemic. Although the virtual format fundamentally differed from the in-person incarnations, the outcomes were potentially complementary. The immersive atmosphere of intensive participatory spaces brings participants together in condensed and energized settings to forge deep and lasting relationships among diverse generations and backgrounds; in a virtual format, they offer discrete opportunities to interface across geographic and other boundaries in shorter bursts and potentially over a longer and more sustained period. Further, the digital format presented opportunities for broader participation among those who might not ordinarily be able to attend these multiday events due to time, financial constraints or mobility issues. While these events did have a fee attached to them, the cost was far lower than face-to-face participation.

The first of these events to take place during the lockdown, Sof Vokh Oystralye, ordinarily marks an annual weekend of events for all ages, held entirely in Yiddish, in a rural location outside of Melbourne, Australia. The event was originally to feature international guests and a series of in-person activities. Instead, the event was held as "Sof-vokh in der heym/Sof-vokh at home" during the same weekend (May 23-24), with a series of interactive activities in Yiddish: conversation and reading groups, song and dance workshops run in Yiddish, and games and activities specifically oriented towards young people. All of the events were conducted using the Zoom platform or on the YiddishOystralye YouTube channel (YiddishOystralye). The keynote featured a virtual Yiddish-language conversation between Melbourne-based Yiddishist Freydi Mrocki and Zalman Mlotek, Artistic Director of the National Yiddish Theater Folksbiene in New York, to discuss the 2018 Yiddish-language adaptation and production of Fiddler on the Roof (Fidler Afn Dakh) (Sof-Vokh at Home). Mlotek's participation was facilitated by a wider phenomenon during the coronavirus lockdowns: the availability of renowned figures in the art world whose hectic schedules would not ordinarily permit their participation in a community event such as this one, especially in a geographically remote location such as Australia. The announcement posted on the website of the event's institutional co-presenter, The Kadimah Jewish Cultural Centre (Melbourne), observed:

The COVID-19 scourge has had some unexpected cultural upsides. Moving out of the bush and onto the internet, Yidish Sof Vokh, the much-loved annual Yiddish retreat, is now freely accessible online this weekend to anyone who wants to practise their conversation, play games, sing, dance or listen to an interesting talk about art and culture - all in Yiddish (Sof-Vokh at Home).

Indeed, the event included international participants who were able to take part in an interactive Australian Yiddish event for the first time. The event reached maximum-capacity attendance for all of its sessions, with participation from Melbourne, across Australia 
and New Zealand, as well as the United States, Israel and European countries. The participants ranged from those born in pre-Holocaust Europe to teenagers. ${ }^{5}$

The annual retreat of Yugntruf (Youth for Yiddish), an American-based organization dedicated to supporting active Yiddish use among young people, likewise shifted the format of its annual Yiddishvokh (Yiddish Week) August gathering, from a camp in Upper New York state to an entirely online format spread over the entire summer under the banner "Yidish-vokh Ale Vokh"! (Yiddish Week Every Week). Over a period of four decades, Yiddishvokh provided an immersive Yiddish-language camping experience, with all activities lived in the language, from interpersonal communication around shared meals, swimming in the lake or playing baseball, to lectures. The announcement released by the group's youth-led leadership emphasized the potential benefits of the 2020 virtual format:

Coming together online this summer has its advantages. Everyone can participate, no matter where you live or if you have mobility issues. With Yidishvokh lasting the whole summer, you can take virtual classes and workshops on a flexible schedule. And most importantly, Yidish-vokh without room, board, and travel expenses will be affordable for everyone [italics in the original] (The Yidish-vokh Committee).

Participants were invited to offer advance input on how to best adapt the programs to a virtual format as well as to lead sessions as part of the virtual events: reading groups, Yiddish courses, lectures, crafting, music, yoga, or coordinating religious services or the talent show. The organizers invited participants to join "for what promises to be - with your help - the biggest Yidish-vokh yet. And this time we can hear and speak Yiddish in ale lender, ale vokh! (in all countries, each week)!" (The Yidish-vokh Committee).

KlezKanada, the largest of the immersive Yiddish events, likewise planned to hold its 25th anniversary Summer Retreat online over a period of four days (August 24-30). The promotional materials released in May promised the same rich array of programming of the in-person retreat, including Yiddish language instruction and lectures in Yiddish. The organizers also expressed a commitment to offering "social gatherings, opportunities for connection, and so much more. We'll be recreating some of our most beloved traditions as best we can while building some new ones for the digital age." Rather than sequestered in a rural location in the Laurentian Mountains outside of Montreal, participants would be able to sign up flexibly for a single session or a pass for the whole event, with student scholarships available for emerging artists and scholars. The organizers promised support in digital literacy for participants as they navigated potentially unfamiliar technologies, as well as programming during different timeslots to facilitate international participation (KlezKanada 2020 is moving online!). In this model, participants spanning the globe would have access to the Canadian festival, widening the global reach of

\footnotetext{
5 The latter were graduates of the local secular Jewish school that teaches Yiddish (Sholem Aleichem College) or members of SKIF (Sotsyalistisher kinder farband/Socialist Children's Union), the Melbourne chapter of the youth arm of the Jewish Labour Bund, which runs regular youth group meetings and camps as well as a Yiddish choir (see Taft 2018), all of which had moved onto an online format during the pandemic.
} 
KlezKanada while also encouraging the integration of different kinds of expertise, experiences and knowledge.

Intensive Yiddish summer study programs, run under the auspices of Yiddish cultural organizations and so seminal to the dissemination of the language and culture among emerging academics, artists and activists, were likewise expressing plans to move fully online by the month of May. For example, the oldest of these programs, New York's Uriel Weinreich Summer Program in Yiddish Language, Literature, and Culture (founded 1968), announced in May: "The program will run in full, with a number of innovations and additions to meet the needs of the virtual classroom. Teaching from New York, Montreal, and Israel, our world-class faculty will join students across the globe as an international community in our own digital Yiddishland" (YIVO-Bard Summer Program). In another example, the Centrum Kultury Jidysz/Center for Yiddish Culture sponsored the online Yiddish Summer Seminar Warsaw as its 18th International Summer Seminar in Yiddish Language and Culture, to be held "in a three-week virtual meeting" through Zoom in JuneJuly (Yiddish Seminar). Significantly reduced tuition fees and no costs for travel and accommodation rendered these programs far more accessible to an international audience.

\section{The Yiddish Chat}

As the most interactive of online Yiddish spaces, the chat or conversation group (shmueskrayz) offers opportunities for participants to connect and interact within a social landscape in Yiddish. In contrast to the formal language class, these sessions promote informal and more spontaneous opportunities for Yiddish use. They also require the most sustained usage of the language and therefore the strongest communicative skills in Yiddish. While pre-existing Yiddish conversation groups moved online, an initiative that emerged directly out of the coronavirus pandemic in its earliest stage was a group under the name Vaybertaytsh Shmueskrayzn. This new project expressed the potential for Yiddish virtual community-building via digital sociality during the coronavirus pandemic and as such will be discussed in depth. 


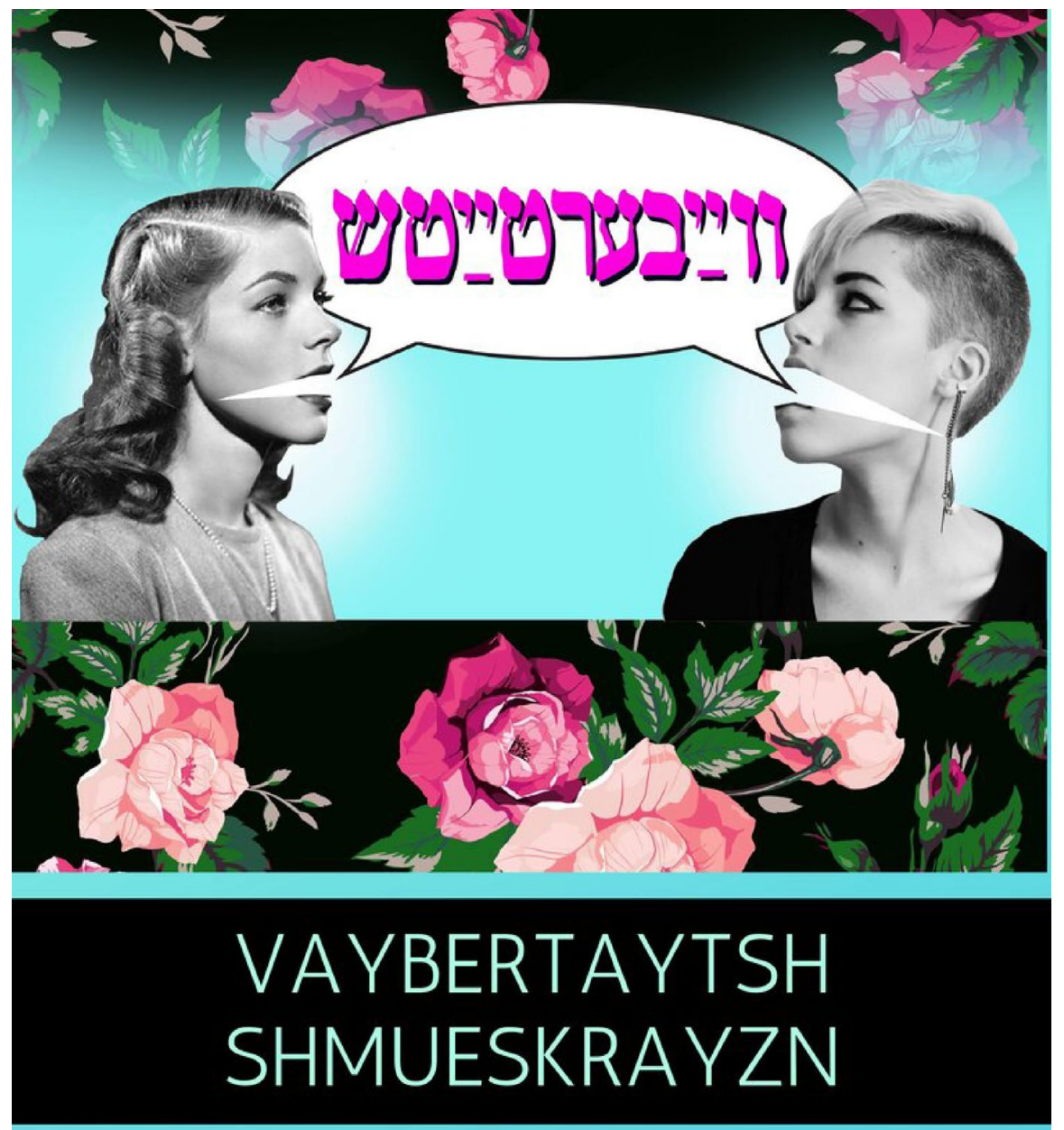

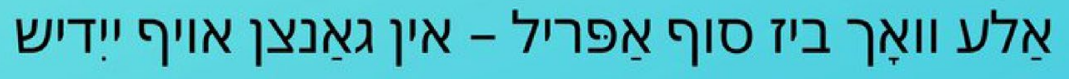

$$
\begin{aligned}
& \text { Visit us on social media or } \\
& \text { www.vaybertaytsh.com/shmueskrayz for details }
\end{aligned}
$$

The Shmueskrayzn (conversation circles) were formed in March by Sandra (Sosye) Fox, the founder and producer of "Vaybertaytsh: A Feminist Podcast. In Yiddish." At the time, Vaybertaytsh was in its fourth year of producing audio content featuring Yiddish-language conversations with artists, activists and innovators, and other speakers across a wide variety of topics - including midwifery, cooking, fashion and the Hasidic 
world - from around the globe; the Vaybertaytsh website (vaybertaytsh.com) had a wide reach, attracting some 8000 hits monthly (Sandra (Sosye) Fox, Zoom interview with the author, 14 May 2020). For Fox, an academic who had acquired her Yiddish as a young adult and was invested in the language and culture, the beginning of the coronavirus quarantines marked a time of frustration and lack of social contact. She sensed that with everyone at home, listeners did not require the solitary act of listening to a podcast as much as an interactive forum to use their Yiddish. The Shmueskrayzn launched on March 19, with a first announcement, posted five days before, first in Yiddish and then in English:

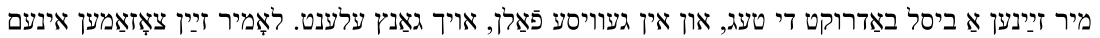

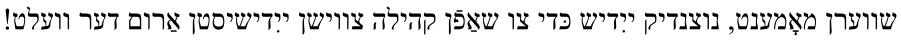

הֵַלטן מיר אַ שמועסקרייז אויפן אינטערנעץ, נוצנדיק ZOOM

We're all a bit stressed out right now, and in certain cases, also pretty lonely. Let's be together in this difficult moment, using Yiddish to make community between Yiddishists around the world! We're holding a conversation circle in Yiddish (FOR ALL LEVELS) using Zoom (A Vaybertaytsh Shmueskrayz). 


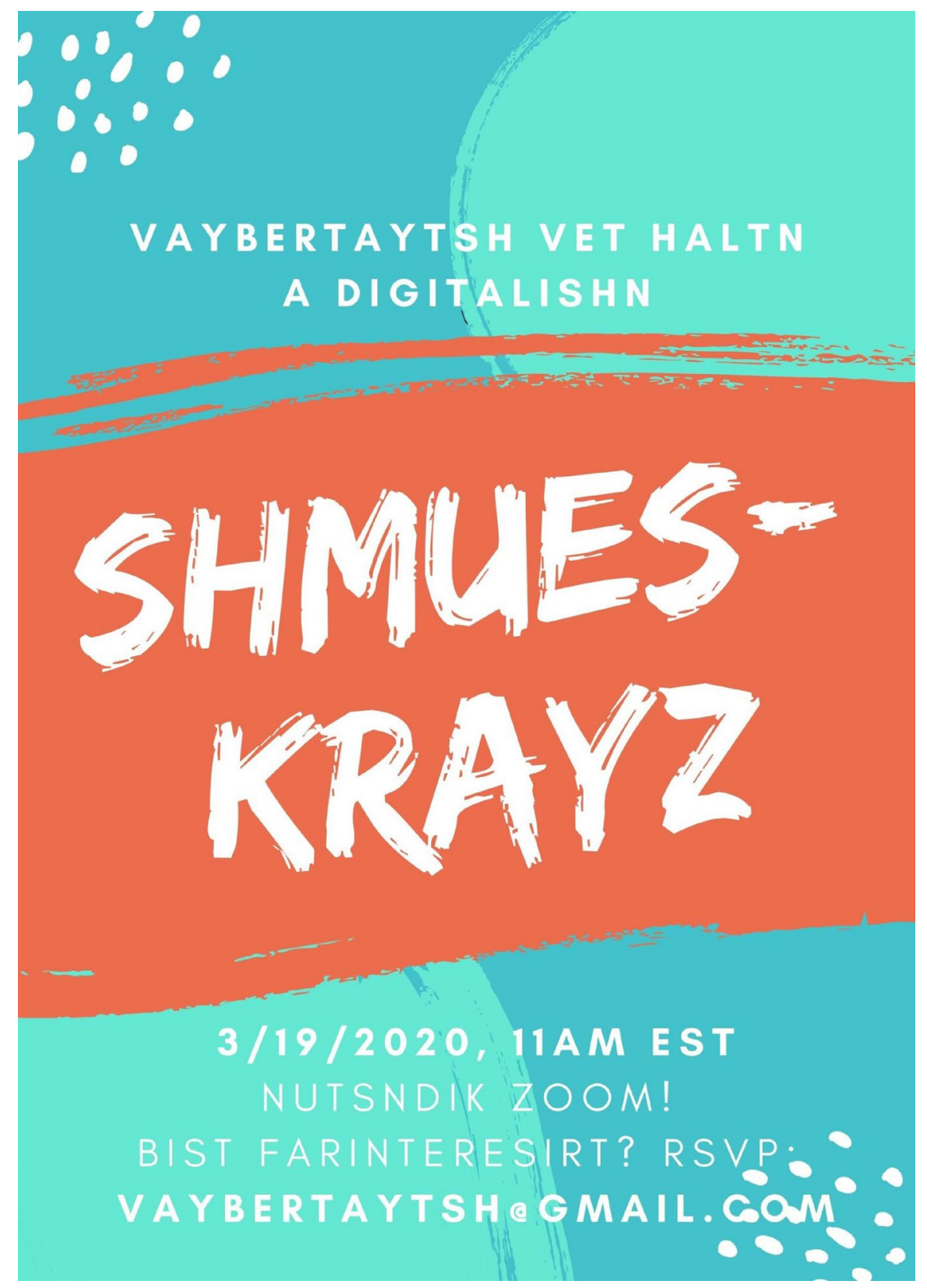

[image of http://www.vaybertaytsh.com/blog/2020/3/13/a-vaybertaytsh-shmue skrayz-af-zoom].

The Shmueskrayzn were promoted as an immersive yet inclusive space for all levels of Yiddish speakers to form a temporary lived community through virtual 
gatherings. The inaugural meeting attracted some 70 participants, which created an involved process of preparation and coordination of breakout rooms led by volunteers. While the original poster stated that the conversation group would meet weekly until the end of April, by mid-May, the numbers were holding steady at 25 per week, including a core of regular participants from locations and time zones worldwide.

The ongoing announcement on the Vaybertaytsh website and through social media points to the evolution of the Shmueskrayzn into a fixture of the secular Yiddish calendar:

For a few weeks (or until social distancing ends), we'll be holding weekly conversation circles on Zoom! Below you'll find the weekly schedule for the next month, a google doc link where the themes for each Shmueskrayz are continuously updated, and the permanent link to our Zoom Room. Schedule: 12PM EST on Thursdays until social distancing is a thing of the past (Vaybertaytsh Shmueskrayzn).

The digital format of the Shmueskrayzn impacted the makeup of the group in diverse ways. As an offshoot of a feminist podcast and promoted on its social media, the Shmueskrayzn emerged as a space for younger Yiddish speakers to engage with the language, with the participants overwhelmingly under 40 years of age. The group comprised primarily North Americans and Europeans, with Fox in Tel Aviv, and was evenly split in terms of gender. It was diverse in political orientation and levels of fluency, including both young people raised in Yiddish homes as native speakers, and newer learners. Each of the participants knew enough Yiddish to express themselves in the language, with the style of Yiddish spoken varying from the Standard Yiddish taught in university classrooms to varied and hybrid Yiddish dialects. While a majority of the regular participants formed part of the secular Yiddish world, two were male members of the New York-area Hasidic communities, who listened more than they spoke (Sandra (Sosye) Fox interview). The Shmueskrayzn suggests implications in the move to online programming around the existing boundaries between largely polarized Hasidic and secular Yiddish spaces, each of which enact their own orientation towards Yiddish, the former oriented towards a collective connection to a traditional Jewish past, and the latter towards Yiddish an expression of individual identity or modern cultural expression. While these boundaries have been blurred in face-to-face gatherings in Yiddish organizations such as Yiddish Farm, an American organic farm that has offered Yiddish-language immersive educational experiences spanning both communities, the transitional period at the onset of the coronavirus pandemic restrictions indicates that these boundaries might be rendered more porous when mediated by technology that allows for virtual gatherings.

The format of the Shmueskayzn addressed a different theme or activity each week, with the focus on universal themes that provided the participants with opportunities to speak comfortably rather than address topics that were overtly political or potentially triggering. For example, one of the most successful sessions addressed the question of sleep during the coronavirus pandemic, where participants shared their dreams. Games such as "Two Truths and a Lie" were also popular. Fox posted the theme for each week on the website, which also featured an exhaustive 
coronavirus vocabulary list prepared by the League for Yiddish that included terms such as face mask, hand sanitizer, quarantine, lockdown, practice self-isolation, and practice social distancing. ${ }^{6}$ This vocabulary list facilitated the participants' ability to speak to their own experiences of the pandemic. With an emphasis on an interactive and normalized use of Yiddish as opposed to the structured model characteristic of Yiddish reading groups, the group established a level of intimacy and comfort over the weeks following its formation. According to Fox, the motivations of the participants included combatting loneliness during lockdown and the opportunity to practice Yiddish (Sandra (Sosye) Fox interview). The initiative had had a profound impact on the well-being of its participants, including Fox. In a Facebook post, she noted:

The Vaybertaytsh Shmueskrayz is basically the best part of my week!! A devoted group of about 25 people who come almost every week has formed, and we also get a few new faces who come some weeks. What has been amazing is that, even without it having a pedagogical purpose or vibe (there's no teaching Yiddish, though people help with words once in a while), everyone's Yiddish - including my own - has become more fluent and confident over the last two months. It is so cool to watch. Video chatting does not replace in person socializing, but for getting people from all over the world together to use Yiddish, it works and is worth all of the shortcomings. Thanks to everyone who came today and in all the past weeks, and to everyone who has helped lead a breakout room [heart emoticon].

One participant, native speaker and Yiddish teacher and researcher Hinde (Ena) Burstin, commented on Fox's post from Melbourne: "I love the shmueskrayz. It's so wonderful to connect with Yiddish speakers around the globe while my city sleeps. It's a highlight of my week too, a great way to finish my Thursdays after two hours of teaching Yiddish via Zoom. Looking forward to seeing you next week xox." Another participant, the abovementioned Alice Che, commented from Kaliningrad: "Yes! I was feeling not good and taking a nap, but $5 \mathrm{~min}$ before the meeting I woke up just like that and was like 'I should see everyone, this is my social life now.' The good thing is: you can lay on a couch and meet 25 mentshn [people] at the same time [emoticon of two thumbs ups]." In mid-May, Fox expressed her intention to continue the Shmueskrayzn indefinitely, barring Zoom fatigue. She observed that by rendering the boundaries between countries porous, the virtual world of Yiddish facilitated bonds between its geographically dispersed participants. She underlined that the expansion of Yiddish materials online could not replace or mimic faceto-face Yiddish activity, but rather was creating something entirely new (Sandra (Sosye) Fox interview).

The Shmueskrayzn embody the ideals of a heterotopic Yiddishland as a social space to engage and empower its participants via a shared vernacular use of Yiddish. As an innovative digital social forum that emerged out of the crisis of the pandemic,

\footnotetext{
${ }^{6}$ The list was originally posted on March 3 on the Yiddish League Facebook page, https://www.faceb ook.com/yidishlige, as one of the first Yiddish-language responses to the pandemic restrictions.
} 
they offer a case study in how communications technologies can support the development of a Yiddish cybervernacular. In this mode, interactive virtual speech communities mediated by communications technologies meet in real time to connect in meaningful and transformative ways.

\section{Discussion}

The COVID-19 pandemic has promoted secular Yiddish digital social landscapes where communications technologies mediate an intense and transformative vernacular engagement with the language via speaking, studying, singing together with others in real time. Because of the wide dispersion of the secular Yiddish world, these activities span multiple time zones, resulting in a digital Yiddishverse where digitally mediated social activity takes place 24 hours a day. The digital heterotopic Yiddishland offers a landscape that participants slip into and out of as part of the rhythm of their regular day, where each discrete activity brings with it its own subcommunity and each enacts its own segment of a secular Yiddish social landscape. In a milieu where the lines between participant and observer/scholar are already blurred - a great many scholars of Yiddish are also producers and consumers of Yiddish culture-the digital Yiddish environment further flattens out distinctions as participants of all ages and backgrounds gather on a shared screen. In a digital secular Yiddishland, where boundaries are porous, possibilities for encounter are far more unfettered by limitations associated with physical location, physical mobility or previous patterns of engagement or expectations. With the digital technology of Zoom allowing participants to select the name under which they appear, participation can occur incognito.

My informants in this study verbalized the significance of the online Yiddish social spaces during the lockdown. They reported how the interactive events within the secular Yiddish world helped to combat the negative effects of social isolation and offered a sense of participation in a virtual community, particularly for those ordinarily geographically remote from the regular hubs of Yiddish activity. From her vantage point as a New York-based musician and facilitator of online Yiddish song workshops, Jeyn Levinson observed that the coronavirus pandemic strengthened the bonds between geographically distanced parts of the Yiddish world by bringing people together more frequently through remote engagements, often in intimate environments (Jeyn Levinson interview). For Alice Che, located in Kaliningrad, Russia, the impact of the coronavirus was to erase boundaries and bring the Yiddish world closer: in addition to producing her own videos, she was able to attend the Vaybertaytsh Shmueskrayz group as well as a regular virtual Yiddish conversation group based in Boston (Alice Che, email interview with the author). Satoko Kamoshido, an academic based at the University of Tokyo, reported that she was attending Yiddish meetings over Zoom four or five times a week as a result of the pandemic restrictions. She expressed feeling like a more integral part of the wider Yiddish world from her vantage point in Japan, a place ordinarily far removed from the centers of Yiddish culture: "In this time, I am feeling that I am one of the many 
isolated Yiddish lovers staying at home. Usually, I feel I am more isolated than others" (Satoko Kamoshido, email interview with the author, 22, 25 May 2020).

In a blog entry published in In geveb in June of 2020, American academic and Yiddish enthusiast Faith Hillis made the following observations about her engagement with Yiddish language and culture during the early months of the pandemic restrictions:

One community in which I was involved-the close-knit world of Yiddish teachers and learners - took no respite for COVID-19. In the first week of the crisis, a Yiddish discussion circle organized by Vaybertaytsh, the feminist podcast founded by Sandy Fox, brought me into my first Zoom room. By the time April turned to May, there was an embarrassment of riches of online Yiddish programming: intensive grammar seminars, open mic nights, singing workshops, even a group reading the recently-translated Harry Potter together. One Sunday in late May, I realized that I had signed up for virtual Yiddishland events that would consume my entire day, including a Yiddish-language yoga class, a celebration of Sholem Aleichem, and a cooking workshop. (Hillis 2020)

The author cited her engagement with Yiddish as a site of transformative human connection and community-building during the crisis. She also shared how Yiddish would offer a collective platform for expressing a radicalized identity during the George Floyd protests against racism and police brutality taking place across the United States beginning in late May.

The activities of the secular Yiddish world during the earliest period of the coronavirus restrictions dovetailed with discourse within the wider Jewish world, where the pandemic early on sparked introspection into the wider, enduring potential of digital Jewish engagement. The Jewish Telegraphic Agency published an online series in May of 2020 under the heading, "Visions for the post-pandemic future." An article titled, "It's time to build digital-first Jewish communities that will outlast the pandemic," called for a reconsideration of what Jewish community and engagement could mean in the digital age:

A few months ago, the digital Jewish ecosystem was relatively sparse. For most institutions, livestreaming a program was rare - the occasional cherry-on-top of the sundae that was in-person Judaism. In just two months, the norms have flipped entirely. The reason that we need to sit with the astonishing nature of this reality is that it represents a change in the entire Jewish world for the years and decades that will come.

The author suggested that digital gatherings could provide opportunities for engagement for people with disabilities, or those seeking involvement outside of or beyond their own communities, and "finding transcendent, supportive communities online." Digital Judaism could offer an opportunity to reimagine community not as a geographic concept but as a group of people who come together around shared interests and commitments (Rofeberg 2020). 
The "new normal" of the pandemic spawned online secular Yiddish spaces that fit the model of "transcendent, supportive communities online": accessibly forming a virtual community via a social landscape that spans geographies and time zones. The realization of a new digital mode of activity for secular Yiddish brought hope for deeper changes to the fabric of the Yiddishverse. Thus, Adam Whiteman, a longtime New York-based Yiddishist, observed at the end of May:

I think we are seeing an amazing blossoming of Yiddish media creativity in all forms. To date we have only seen Yiddish on-line classes. Now we are seeing a range of creative expression by Yiddish performers. We are also starting to see online lectures like the one the Yiddish League is doing on Sunday and Monday [Miriam Trinh's Di pandemye-akademye/Pandemics Academics, May 24-25]. I really hope that this level of creativity will continue and that a positive outcome of this COVID-19 nightmare will be the expansion of quality Yiddish-language offerings to speakers around the world, further unifying this community. From a financial perspective, I hope that entertainers, especially theaters, will see that there is a worldwide audience [for] which they can monetize their product through subscriptions and on-line performances (Adam Whiteman, Facebook Messenger interview with the author, 22 May 2020).

For secular Yiddish, the leap into cybercommunity spurred by the pandemic occurred with particular vigor because of the foundations in digital engagement already in place when the coronavirus pandemic began.

The coronavirus virtual Yiddishverse evinced a differential impact for the various segments of the Yiddish world while also revealing the limitations of the mode of online engagement. First, while the pandemic facilitated access to a variety of activity for Yiddish affinity groups such as new learners, the economics of the lockdowns also entailed lost income and uncertainty about the future for those deriving their income from Yiddish activity, notably performing artists. This raises deep questions around how the cultural producers of the Yiddish world might create sustainable models for engagement in a virtual Yiddishland. Second, the Yiddish activity under discussion was not equally accessible to all, with the restrictions of the pandemic compounding scarcity around time, especially for those balancing working from home with supervising the online schooling of their children. Third, the existing communication technologies did not facilitate all aspects of Yiddish engagement equally, as activities conducted on digital communication platforms such as the Zoom room tended to remain by necessity mediated by a teacher, lecturer or moderator. While the 2020 technologies supported the delivery of formalized events such as lectures or performances to an audience, they required extensive structuring to facilitate verbal interaction among participants and did not support spontaneous conversation among multiple participants or participatory music activities such as collective singing. The planned and mediated nature of interactions in these digital media position them as an extension of postvernacularity, with Yiddish engagement as deliberate and performative in comparison with the potential for spontaneous exchange possible in face-to-face encounters. While the coronavirus model of Yiddish activities facilitated experimental initiatives using new digital technologies that will no doubt have a lasting impact, they do not yet offer an enduring model for the 
unmediated Yiddish cybercommunity that Sadan envisioned a decade ago. Without the ready availability of the technology to facilitate a truly immersive virtual reality environment, the virtual Yiddish community remained in two dimensions, mediated by hosts, screens, the quality of internet connections and microphones, and susceptibility to "Zoom fatigue" (the exhaustion of excessive time spent on video communications platforms). The early stages of "new normal" determined that Yiddish enthusiasts gravitated towards Yiddish in times of enforced isolation. More enduring models for building secular Yiddish digital community will require fully developed virtual reality technology that is more conducive to unmediated social interaction and deeper immersion.

\section{Concluding Remarks a Year Later (May 2021)}

The normalization of digital technology in the secular Yiddish world during the pandemic has spurred new initiatives and possibilities for community-building beyond the period under discussion. A year after the onset of the pandemic restrictions, organizations and individuals continue to join the virtual secular Yiddish social landscape to offer an eclectic array of programming. In the crisis of the early pandemic restrictions in March of 2020, Yiddish activities emerged piecemeal as one means of coping with the traumatic experiences of lockdowns and isolation; while individual projects may have run their course, the uses of digital technology as a medium for socializing, education and cultural production have endured. Due to the short time frames of this study, the deep digital ties through shared identities and relationships via an online platform had not yet crystalized, nor had the implications of new expressions of Yiddish digital subcultural sociality. Even in an eventual return to live, in-person activities and international travel, one can expect a hybrid Yiddishverse combining in-person and online engagement as digital communications technologies continue to evolve. The virtual and heterotopic mode of engagement that gained traction across the secular Yiddish world offered a taste of the possibilities. The abovementioned Hinde (Ena) Burstin shared the following observations from Australia a year after the period under discussion:

Di pandemiye hot tseshmeltst di grenetsn tsvishn lender un tsvishn Yidishredndike kehiles. Az ikh hob zikh nor gekent trefn mit mayne hige fraynd durkh Zoom, iz mer nisht geven keyn khilek tsvishn Melburn un Nyu York (oyser loyt der tsayt-zone, ober ikh bin say vi say fun der natur vakh baynakht). Di Yidish velt hot zikh oyfgeefnt far mir. Farayorn hob ikh gepravet finf sdorim. Un ikh hob onteylgenumen in on a shir aktivitetn in oysland, un ikh tu dos nokh itst. L'moshl, eyernekhtn (d"h zuntik bay nakht) hob ikh forgeleyent a nay Yidish lid mayns in London Yidish-shtub's Yiddish Open Mic, far an oylem fun 50 yidish-redners fun iber der velt. Un haynt baynakht vel ikh lernen a Yidish literatur klas, oyf Yidish, in University of Chicago. Far der pandemiye volt dos nisht geven meglekh.

The pandemic has dissolved the boundaries between countries and between Yiddish-speaking communities. So long as I could only meet my local friends 
over Zoom, there was no longer any difference between Melbourne and New York (aside from the time zone, but I am by nature a night owl). The Yiddish world opened for me. And I participated in an endless array of activities abroad, which I continue to do today. For example, on Sunday night I recited a new poem of mine at the London Yiddish Open Mic [Café] for an audience of 50 Yiddish speakers from across the world. And this evening, I will be teaching a Yiddish literature course, in Yiddish, at the University of Chicago. Before the pandemic, this would not have been possible. (Hinde Burstin, email to the author, 18 May 2021).

The COVID-19 pandemic dramatically accelerated elements of a cybervernacular Yiddishland. It has prompted a virtual, inclusive and inter/multigenerational social landscape that brings together the creative forces of the Yiddish world and where the language is enacted in a digital environment in deeply meaningful and transformative ways. The virtual Yiddishland of the early pandemic served to defragment a segmented secular Yiddish world comprised of multiple geographic centers and subcommunities as long-standing silos surrounding Yiddish activity fell away, even if only temporarily. With its deep historic associations with progressive, leftist politics, Queer Yiddishkeit, and less hegemonic or more marginal identities, the digital Yiddishverse offers opportunities for transformative connection among those seeking alternatives to mainstream identification, whether Jewish or non-Jewish, to actively engage with the language across multiple modes: study, conversation, singing, and, perhaps most importantly, meeting new friends. A virtual secular Yiddishland grounded in cutting-edge communications technologies can bring to prominence the younger members of the Yiddish milieu as well as newcomers, who bring their own vision to the social landscape. The digital Yiddishverse offers a site for Yiddishists who are dispersed across the globe to gather and build virtual, accessible and interconnected communities of their own design. The next frontier will be the creation of a fully immersive digital Yiddishland.

\section{References}

Abrams, Nathan. 2017. Film, Television and New Media Studies. In The Routledge handbook of contemporary Jewish studies, ed. Laurence Roth and Nadia Valman, 108-120. New York: Routledge.

Avineri, Netta. 2014. Yiddish Endangerment as Phenomenological Reality and Discursive Strategy: Crossing into the Past and Crossing Out the Present. Language and Communication 38: 18-32.

Biale, David, et al. 2018. Hasidism: A new history. Princeton, NJ: Princeton University Press.

Campbell, Heidi, ed. 2015. Digital Judaism: Jewish negotiations with digital media and culture. London: Taylor \& Francis Group.

Cohen, Hagit. 2008. The demands of Integration-The challenges of ethnicization: Jewish women's Yiddish reading circles in North America between the Two world wars. Nashim 16: 98-129.

Glaser, Amelia. 2017. The idea of Yiddish; Re-globalizing North American Jewish culture". In The Routledge handbook of contemporary Jewish studies, ed. Laurence Roth and Nadia Valman, 259-271. New York: Routledge.

Goldman, Shalom. 2020. Yiddish plague songs.” Tablet Magazine. https://www.tabletmag.com/sections/ arts-letters/articles/yiddish-plague-songs. Accessed 23 May 2020.

Hillis, Faith. 2020. On learning Yiddish in a pandemic. In geveb. https://ingeveb.org/blog/on-learningyiddish-in-a-pandemic. Accessed 8 July 2020. 
Ingall, Marjorie. 2019. How Sweden became the epicenter of Yiddish children's media. Tablet Magazine. https://www.tabletmag.com/sections/community/articles/sweden-yiddish-childrens-media. Accessed April 2, 2020.

Katz, Dovid. 2019. The Yiddish conundrum: A cautionary tale for language revivalism. In The Palgrave handbook of minority languages and communities, ed. Gabrielle Hogan-Brun and Bernadette O’Rourke, 553-587. London, UK: Palgrave Macmillan.

Jordan Kutzik. 2020. Amidst coronavirus pandemic, YIVO looks to the digital future, Forward. https:// forward.com/yiddish/447163/yivo-pandemic-online-classes-digitization-yiddish-culture/. Accessed 4 June 2020.

Jordan Kutzik. 2019. "Yiddish duolingo dialect question a subject of great interest," Forward. https:// forward.com/yiddish/435240/yiddish-duolingo-dialect-question-a-subject-of-great-interest/ Accessed June 3, 2020.

Kraut, Robert E., Paul Resnick, and Sara Kiesler. 2011. Building successful online communities: Evidence-based social design. Cambridge, Mass.: MIT Press.

Legutko, Agnieszka. 2016. Yiddish in the $21^{\text {st }}$ Century: New media to the rescue of endangered languages," Handbook of foreign language education in the digital age, edited by Lisa Winstead and Penny Wang, 236-251. Hershey, Pennsylvania: IGI Global, 2016.

Nove, Chaya R. 2018. The Erasure of Hasidic Yiddish from Twentieth Century Yiddish Linguistics". Journal of Jewish Languages 6: 109-141.

Parigi, Paolo, and Rachel Gong. 2014. From Ggrassroots to digital ties: A case study of a political consumerism movement.". Journal of Consumer Culture 14: 236-253.

Rabinovitch, Lara, et al. (eds.). 2012. Choosing Yiddish. Detroit: Wayne State University Press.

Ragusa, Angela, and Olivia War. 2016. Caught in the web: Male Goths using online ICTs to transcend rural reality.". Communication, Politics \& Culture 49: 1-24.

Rofeberg, Lex. 2020. It's time to build digital-first Jewish communities that will outlast the pandemic," Jewish telegraphic agency. https://www.jta.org/2020/05/19/opinion/its-time-to-build-digital-firstjewish-communities-that-will-outlast-the-pandemic. Accessed April 12, 2020.

Sadan, Tsvi. 2011. Yiddish on the internet. Language \& Communication 31: 99-106.

Scolnic, Ellen and Joyce Eisenberg. 2020. These 10 Yiddish Words Will Get You Through Quarantine." Jewish Telegraphic Agency. https://www.jta.org/2020/05/20/culture/these-10-yiddish-words-willget-you-through-quarantine. Accessed June 6, 2020.

Shandler, Jeffrey. 2006. Adventures in Yiddishland: Postvernacular language and culture. University of California Press.

Shandler, Jeffrey. 2017. Holocaust memory in the digital age: Survivors' stories and new media practices. Stanford: Stanford University Press.

Taft, Margaret, and Andrew Markus. 2018. A second chance: The making of Yiddish Melbourne. Clayton, Australia: Monash University Publishing.

Waldman, Rose. 2018. Seizing the means of cultural production: Hasidic representation in contemporary Yiddish media." In geveb. https://ingeveb.org/blog/seizing-the-means-of-cultural-production-hasid ic-representation-in-contemporary-yiddish-media. Accessed August 22, 2020.

Webb, Lucy. 2020. Covid-19 Lockdown: A perfect storm for older people's mental health. Journal of psychiatric and mental health nursing. https://onlinelibrary.wiley.com/doi/https://doi.org/10.1111/ jpm. 12644

Wood, Abigail. 2016. And we're all brothers: Singing in Yiddish in contemporary North America. London, New York: Routledge.

Yudelson, Larry. 2019. A new and very Yiddish Hallelujah. The Jewish Times https://jewishstandard. timesofisrael.com/a-new-and-very-yiddish-hallelujah/. Accessed May 16, 2020.

\section{Websites and social media references}

A Chasene in Shtetl (2016 concert) watch party! Dora Wasserman Yiddish Thearre, https://www.faceb ook.com/events/2559744624339815/, Accessed 24 May 2020.

A Vaybertaytsh Shmueskrayz (af Zoom)! http://www.vaybertaytsh.com/blog/2020/3/13/a-vaybertaytshshmueskrayz-af-zoom. Accessed 14 May 2020.

Der 8 Merts: International Women's* Day (af yiddish, eng+rus sub), https://www.youtube.com/watch?v= 9hMQdwpX7fQ. Accessed 27 May 2020. 
Di pandemye-akademye/Pandemics Academics, May 24-25, 2020, Yidish lige/League for Yiddish, http:// www.leagueforyiddish.org. Accessed 24 May 2020.

Forward Staff, Learn Yiddish with the Forverts' Word of the Day videos. Accessed 10 May 2020.

Idishe Shtub MX, https://www.facebook.com/ShtubMx/?ref=page_internal. Accessed 24 May 2020.

In Eynem: The new yiddish textbook, https://www.yiddishbookcenter.org/language-literature-culture/ yiddish-language-learning/eynem-new-yiddish-textbook. Accessed 27 May 2020.

In Geveb, https://ingeveb.org/. Accessed 12 May 2020.

KlezKanada 2020 is moving online! https://klezkanada.org/news/klezkanada-2020-is-moving-onlineklezkanada-2020-sera-en-ligne/. Accessed 19 May 2020.

Save the Music. Today 3 Jewish events from all over the world. Enjoy each of them and have an extraordinarily good Sunday. https://savethemusic.com/2020/05/23/today-3-jewish-events-from-all-overthe-world-enjoy-each-of-them-and-have-an-extraordinarily-good-sunday/. Accessed 24 May 2020.

Sof-Vokh at Home, Kadimah, https://www.kadimah.org.au/event/sof-vokh-at-home/. Accessed 28 May 2020.

The Digital Yiddish Theatre Project, https://web.uwm.edu/yiddish-stage/, accessed 21 May 2020.

The Oychestra. Sam's Bulgar. https://youtu.be/bYR3Fh_u7DU. Accessed 22 May 2020.

The Yidish-vokh Committee and the Yugntruf Executive Board, "Dear Yugntrufnikes and Yidish-vokhnikes,” https://yugntruf.org/yiddish-vokh/?lang=en. Accessed 29 May 2020

Vaybertaytsh, https://www.vaybertaytsh.com. Accessed 14 May 2020.

Vaybertaytsh Shmueskrayzn, http://www.vaybertaytsh.com/shmueskrayz, accessed 14 May 2020.

Workers Circle Yiddish, https://www.circle.org/yiddish, accessed 21 May 2020.

\#Yiddishalive, https://www.facebook.com/hashtag/yiddishalive. Accessed May 29, 2020.

Yiddish Arts and Academics Association of North America, https://www.facebook.com/YiddishCulture/. Accessed 28 May 2020.

Yiddish Book Center, https://www.yiddishbookcenter.org/about-us; Digital Yiddish Library, accessed 20 May 2020

Yiddish Forward, https://forward.com/yiddish/, accessed 12 May 2020.

Yiddish Open Mic Café, https://www.facebook.com/yiddishopenmic/. Accessed 24 May 2020.

YiddishOystralye, https://www.youtube.com/user/YiddishOystralye. Accessed 28 May 2020. Yiddish Radio Project, Yiddishradioproject.org, accessed 21 May 2020.

Yiddish Seminar, Centrum Kultury Jidysz, http://jidyszland.pl/en/yiddish-seminar/. Accessed 28 May 2020.

Yiddish Terms of the Day - Terms of Endearment, https://www.youtube.com/watch?v=JQ2Fuz8Ljbo\& feature=youtu.be. Accessed 29 May, 2020.

Yiddish \& Yoga in Yerushalayim, https://www.verele.com. Accessed 29 May 2020.

YIVO-Bard Summer Program, https://summerprogram.yivo.org/. Accessed 27 May 2020.

Publisher's Note Springer Nature remains neutral with regard to jurisdictional claims in published maps and institutional affiliations.

Rebecca Margolis is Director and Pratt Foundation Chair of Jewish Civilisation at Monash University's Australian Centre for Jewish Civilisation. Her areas of research focus on the Jewish migrant experience and the transmission and revitalization of the Yiddish language. She is the author of Jewish Roots, Canadian Soil: Yiddish Culture in Montreal, 1905-1945, and the forthcoming volume, Yiddish lebt! Strategies of Language Transmission. She is currently working on a project called "New Yiddish Cinema," which examines a corpus of film and television with Yiddish dialogue that has appeared over the last 20 years. 